\title{
Selective mortality of larval Japanese seabass in Ariake Bay, Japan
}

\author{
Md. Shahidul Islam · Keita W. Suzuki • \\ Yoh Yamashita
}

Published online: 3 September 2009

(C) Springer Science+Business Media B.V. 2009

\begin{abstract}
This article describes the growth, mortality, and selection patterns in early larval stage of Japanese seabass Lateolabrax japonicus in Ariake Bay, Kyushu, Japan. Japanese seabass larvae were collected from the spawning ground in December 2007, and juveniles were collected from the nursery ground in March 2008. Otoliths were analyzed to produce daily records of size-at-age and growth rate
\end{abstract}

This online version of the original article can be found under doi:10.1007/s10452-009-9271-6.

Introduction to the errors and the corrections made in this erratum: This authors apologize that the original of the above mentioned article contains some serious errors that are corrected in this erratum. Figure 3 in the original article shows that larval size is decreasing at $0-8$ days but this is not realistic; in normal circumstances, size should increase with age. Our investigations have confirmed that the size-at-age presented in Figure 3 in the original article was incorrect and that the error was caused by the model used for backcalculation of size from otolith radius (OR). When we plotted OR-at-age as proxy for size-at-age, we found that size was actually increasing consistently with age (see the new Fig. 3 in this erratum) confirming that the back-calculated sizes were incorrect.

We used the 'biological intercept' method (BIM) for backcalculating size-at-age. The method gave incorrect size estimates, possibly because of two reasons: (i) the method assumes a linear relationship between OR and fish size but the relationship was allometric in our study; and (ii) values of the biological intercept (fish size and OR at first feeding) used in the model were perhaps not applicable for larvae in this study. In addition, the BIM itself is often biased and produce erroneous size-at-age estimates (see Takasuka et al. 2004 for that were compared between larvae and juveniles to determine whether selective mortality occurred. A weight-specific growth coefficient $(G)$ and instantaneous mortality coefficient $(M)$ were computed, and the recruitment potential was evaluated from the ratio of $M: G$. Selection for fast-growing and bigger larvae was evident during the 5-14 days after hatching (DAH). Selective mortality acted to preferentially remove fish that were slow growing and/or relatively small members of the cohort at least during the period

discussion). In order to avoid possible biases and errors from back-calculation, many previous studies have used otolith data only and not back-calculated data (e.g., Hare and Cowen 1995; Searcy and Sponaugle 2001; Shima and Findlay 2002) because otolith data are more direct than back-calculated data. In order to correct the errors, we have omitted the backcalculation step and presented the otolith data in this erratum. Since there was highly significant relationship between OR and fish size (standard length, $L$ ), we used otolith daily increment width (DIW) as a proxy for growth rate and OR-atage as a proxy for size-at-age. The original Fig. 3 has been completely replaced by a corrected version and corresponding changes have been made in the texts. Since DIW data has been added to show growth history in the new Fig. 3, the original Fig. 4 is no more useful and has been deleted. The reference Islam et al. (2009) has been updated.

Md. S. Islam · Y. Yamashita

Maizuru Fisheries Research Station, Field Science

Education and Research Center, Kyoto University, Maizuru, Kyoto 625-0086, Japan 
examined. Trends in the growth rate differences between larvae and juveniles suggested that the selection process continued beyond $14 \mathrm{DAH}$ although the exact duration over which selective mortality occurred was unknown. Survivors of Japanese seabass exhibited traits consistent with all aspects of the 'growth-mortality' hypothesis: faster growth, larger size-at-age, and shorter larval stage duration (LSD), i.e., larvae with faster growth, bigger size-at-age and a shorter LSD selectively survived the larval period. Larvae had higher $M(0.323)$ than $G(0.159)$, resulting in the $M: G$ ratio of $>1.0(M: G=2.031)$, suggesting that the larval cohort was rapidly losing biomass. Future studies should look to determine the duration over which selective mortality occurs and the timing of transition between $M$ and $G(M=G)$ and accumulation of cohort biomass.

Keywords Selective mortality ·

Growth coefficient - Mortality coefficient .

Recruitment potential · Japanese seabass .

Lateolabrax japonicus · Ariake Bay

\section{Introduction}

Marine fish larvae generally experience high mortalities that do not always occur in a random manner; rather, mortality is often growth and size selective, preferentially removing slow-growing and smaller individuals from a cohort (Meekan et al. 2006; Takasuka et al. 2003, 2004; Robert et al. 2007). Survival is increased by faster growth and larger body size during early life stages (Hovenkamp 1992; Hare and Cowen 1997; Takasuka et al. 2003, 2004). Larval fishes with a high growth rate can complete the larval stage, the period of high and variable mortality, and can metamorphose into juvenile stage in a shorter

\footnotetext{
K. W. Suzuki

Graduate School of Agriculture, Kyoto University, Kyoto 606-8502, Japan

Present Address:

Md. S. Islam ( $\square)$

Alfred Wegener Institute for Polar and Marine Research, Wadden Sea Station, Hafenstrasse 43, 25992 List auf Sylt, Germany

e-mail: dr.md.islam@gmail.com; sislam@awi.de
}

time after which, mortality rates generally decrease (Houde 1996). Consequently, the concept that larger or faster growing larvae are more likely to survive has been widely accepted.

Growth-related survival mechanisms operate in different timing and duration among fish species, reflecting the features of early survival strategy of each species. For example, in tropical fishes, growthrelated survival mechanisms operate over short time because of a short larval stage duration (LSD) (as short as $\sim 10$ days) resulting from high growth rates (Houde and Zastrow 1993). In contrast, in most temperate fishes, growth rate effects on survival operates over a relatively long duration ( $>50$ days) in the early life stages because of slow growth rates and, therefore, a longer LSD (Meekan and Fortier 1996; Takahashi and Watanabe 2004). Thus, the effects of growth-related survival mechanisms are expected to be much more prolonged in temperate fishes than in tropical fishes as well as in slow-growing fishes than in fast-growing fishes.

Japanese seabass (Lateolabrax japonicus Cuvier 1828 ) is distributed in coastal waters around Japan and is of high commercial and recreational importance. In Ariake Bay, spawning of the fish occurs during November-February off Kumamoto, about $40 \mathrm{~km}$ south from the mouth of the Chikugo River (Fig. 1). Larvae are passively transported northward to the river mouths and shallow surf zones at the upper part of the bay. Transition larvae and early juvenile (14-15 mm of standard length) Japanese seabass ascend to the Chikugo River (Matsumiya et al. 1982). The early life history of this temperate seabass is characterized by slow growth rates (Matsumiya et al. 1982, 1985; Shoji and Tanaka 2007a, b) and relatively long LSD (49-72 days; Shoji et al. 2006). Slow growth rates and long LSD mean an extended duration of vulnerable stags and imply that any effect of growth rate operates over a long duration in this fish. Previous studies have suggested that recruitment variability in most marine fishes is largely determined by the demographic changes that occur during the larval stages (Houde 1997). Most previous studies addressing the growth and mortality of Japanese seabass, however, concentrated in postsettled, juvenile populations (Matsumiya et al. 1982, 1985; Shoji et al. 2006; Shoji and Tanaka 2007a, b) and very little is known on the growth and survival processes during the early larval stages. The aim of 


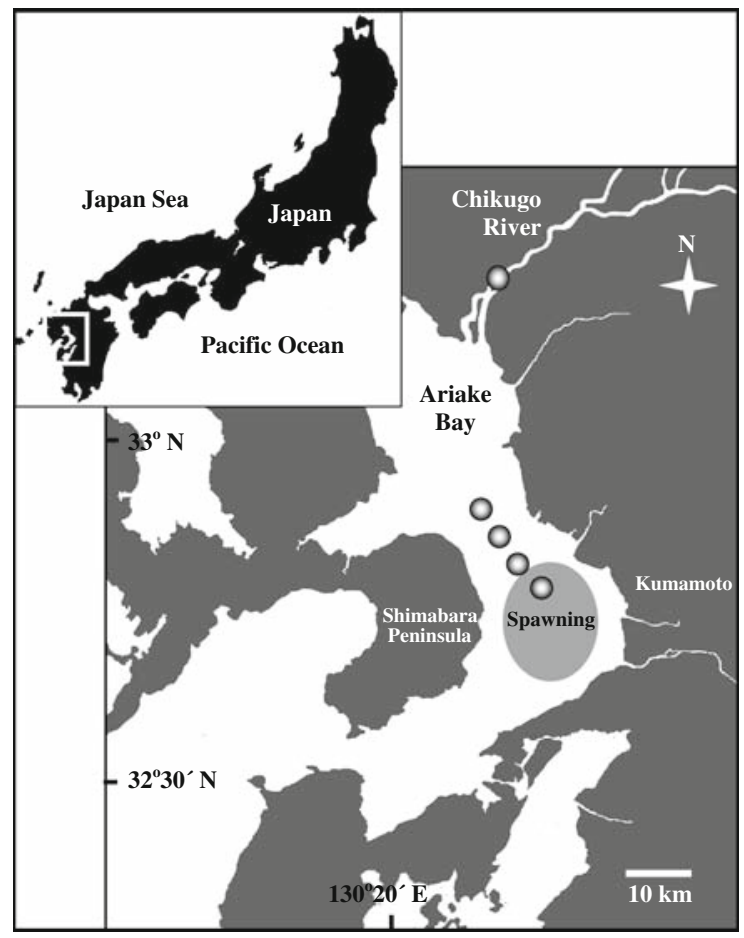

Fig. 1 Map of Ariake Bay showing the sampling stations for larvae (near the spawning ground in the bay) and juveniles (in the nursery ground in Chikugo River)

the present study was to investigate the growth and mortality during early larval stages of Japanese seabass and to identify if mortality is growth- and size-dependent in larval Japanese seabass in Ariake Bay.

\section{Materials and methods}

The study area has been described in our previous paper (Islam and Tanaka 2006) and is shown in Fig. 1. Cruises for collecting larvae of Japanese seabass were made on December 17, 2007 and January 11, 2008 near the spawning ground; in January, however, no larvae were caught. Juveniles were collected from the Chikugo River estuarine nursery areas on March 21, 2008. A conical ichthyoplankton net $(1.3 \mathrm{~m}$ mouth diameter, $0.33 \mathrm{~mm}$ mesh) equipped with a flowmeter was towed from a boat at a velocity of $\sim 1 \mathrm{~m} \mathrm{~s}^{-1}$. Japanese seabass larvae and juveniles were sorted and preserved in $99 \%$ alcohol on board. Standard length $(L, \mathrm{~mm})$ of each larva and juvenile was measured to the nearest $0.1 \mathrm{~mm}$; larval and juvenile density $(D$, number $100 \mathrm{~m}^{-3}$ ) was calculated.

Sagittal otoliths of larvae and juveniles were removed under a microscope and mounted with epoxy resin on glass slides. Otoliths of juveniles were polished to the core on lapping films in order to get clear view of the daily growth rings; otoliths of larvae did not require polishing. The number of daily growth rings was counted, and the radius of each ring from the otolith nucleus as well as the distance from the nucleus to the margin (otolith radius, OR) were measured using a light microscope connected with a video monitor and otolith reading system (ARP/W, Ratoc System Engineering Co. Ltd, Tokyo, Japan). The relationship between $L$ and OR was best fitted by an allometric formula. Since the $L-$ OR relationships were highly significant (see 'Results'), we used otolith daily increment width (DIW) as a proxy for daily growth rate and OR-at-age as a proxy for size-at-age.

Assuming that the juveniles collected in March 2008 originated and survived from the larval population collected in December 2007 (see "Discussion" section), DIW and OR-at-age were compared between larvae and juveniles (original population and survivors, respectively) for each of 5-14 days of larval life. Student's $t$ test was used for this comparison. Overall growth rate $(\mathrm{Gr})$ of larvae and juveniles from hatching to capture was calculated as: $\mathrm{Gr}=\left(L_{\text {catch }}-L_{0}\right) / A$, where $L_{\text {catch }}$ is the larval and juvenile $L$ at capture, $L_{0}$ is the mean $(n=20) L$ of newly hatched larvae obtained from hatchery, which was estimated as $3.7 \mathrm{~mm}$, and $A$ is the corresponding age in days.

In order to calculate the weight-specific growth coefficient, larval and juvenile Japanese seabass from a different sample were dried for $24 \mathrm{~h}$ at $45^{\circ} \mathrm{C}$ and weighed on a microbalance scale to the nearest $0.1 \mathrm{mg}$. Relationship between $L(\mathrm{~mm})$ and dry body weight $(W, \mathrm{mg})$ was established using regression analysis. The regression equation $\left(W=4 * 10^{-5} L^{4.307}\right.$; $R^{2}=0.959 ; n=180$ ) was used to calculate the dry weight from $L$ of the larvae in this study. The weightspecific growth coefficient $(G)$ was estimated as: $W t=W_{0} \exp (G t)$, where $W t$ is the weight (mg) at time $t$ (days), $W_{0}$ is the weight of larvae in the previous age group in consideration, and $G$ is the weight-specific growth coefficient.

Instantaneous mortality coefficient $(M)$ was estimated as: $N t=N_{0} \exp (-M t)$, where $M$ is the 
instantaneous daily mortality coefficient, $N t$ is the estimated density of larvae at age $t$ (days), and $N_{0}$ is the estimated density of larvae in the previous increment group in consideration. Relative recruitment potential of Japanese seabass was assessed by examining the ratio of $M: G$ (Houde 1996, 1997).

\section{Results}

A total of 30 larvae were collected by 5 tows (30 min per tow) and 35 juveniles were collected by 7 tows ( 10 min per tow) with a mean density of 0.473 larvae $100 \mathrm{~m}^{-3}$ and 0.676 juveniles $100 \mathrm{~m}^{-3}$. Plots of larval standard length $(L, \mathrm{~mm})$ on otolith radius $(\mathrm{OR}, \mu \mathrm{m})$ and on age $(A$, days) for the larval and juvenile Japanese seabass were expressed by allometric relationships that were highly significant $(P<0.001)$. The equations are as follows (Fig. 2): OR $=1.024 * L^{1.898}\left(R^{2}=0.983 ; n=65\right)$ and $A=$ $0.577 * L^{1.702}\left(R^{2}=0.969 ; n=65\right)$.

Comparison of DIW (growth rate) and OR-at-age (size-at-age) between larvae and juveniles revealed that the Japanese seabass larvae underwent strong selective mortality during 5-14 DAH (each day from the 5 th to the 14th day). Those larvae that survived to the juvenile stage had significantly higher growth rates and were significantly larger at the specified age (Student's $t$ test; $P<0.01$; Fig. 3) than the larval population from which they were sourced.

Relationships between larval body weight $(W, \mathrm{~g})$ and age ( $A$, days) were expressed as (Fig. 4): $W=9.9 * 10^{-3} * \exp (0.159 A)$. The decline in larval density $\left(D\right.$, number of larvae $\left.100 \mathrm{~m}^{-3}\right)$ at age $(A$, days) was expressed by following exponential regression (Fig. 4): $D=1.034 * \exp (0.323 A)$. Using the daily mortality coefficient $(M)$ and weight-specific growth coefficient $(G)$, the ratio of $M: G$ was estimated to be 2.031. Overall mean $( \pm \mathrm{SD})$ growth rate from hatching to capture was $0.164 \pm 0.060 \mathrm{~mm} \mathrm{day}^{-1}$ in larvae and $0.181 \pm 0.035 \mathrm{~mm} \mathrm{day}^{-1}$ in juveniles.

\section{Discussion}

In field tests based on characteristics of survivors versus original population, an assumption that both of them originated from the same population is essential (Hovenkamp 1992, Meekan and Fortier 1996,
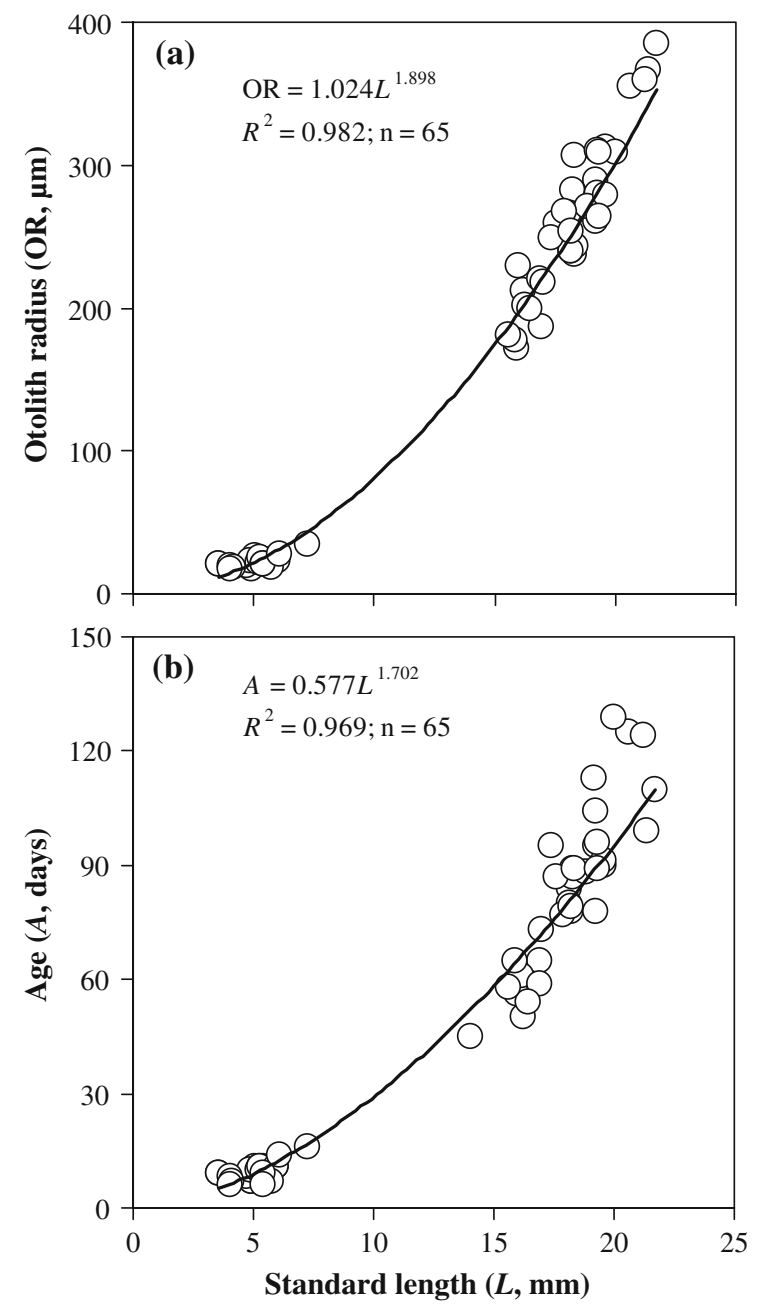

Fig. 2 Relationships of larval and juvenile standard length ( $L$, $\mathrm{mm})$ with a otolith radius (OR, $\mu \mathrm{m})$ and $\mathbf{b}$ age $(A$, days) of Japanese seabass collected from Ariake Bay

Takasuka et al. 2004). In Ariake Bay, spawning of Japanese seabass occurs in offshore waters off Kumamoto and Shimabara Peninsula, $\sim 40 \mathrm{~km}$ off the Chikugo River mouth (Fig. 1). Larvae are dispersed and transported by residual currents from the spawning ground to the nursery areas that are formed in shallow nearshore waters and in the Chikugo River estuary. Late larval and early juvenile Japanese seabass concentrate in large numbers in the low salinity areas of the Chikugo River, which is one of the most important nursery habitats for Japanese seabass in Ariake Bay. This life history suggests that the larvae and juveniles are restrictedly distributed in areas between the spawning ground and the nursery 

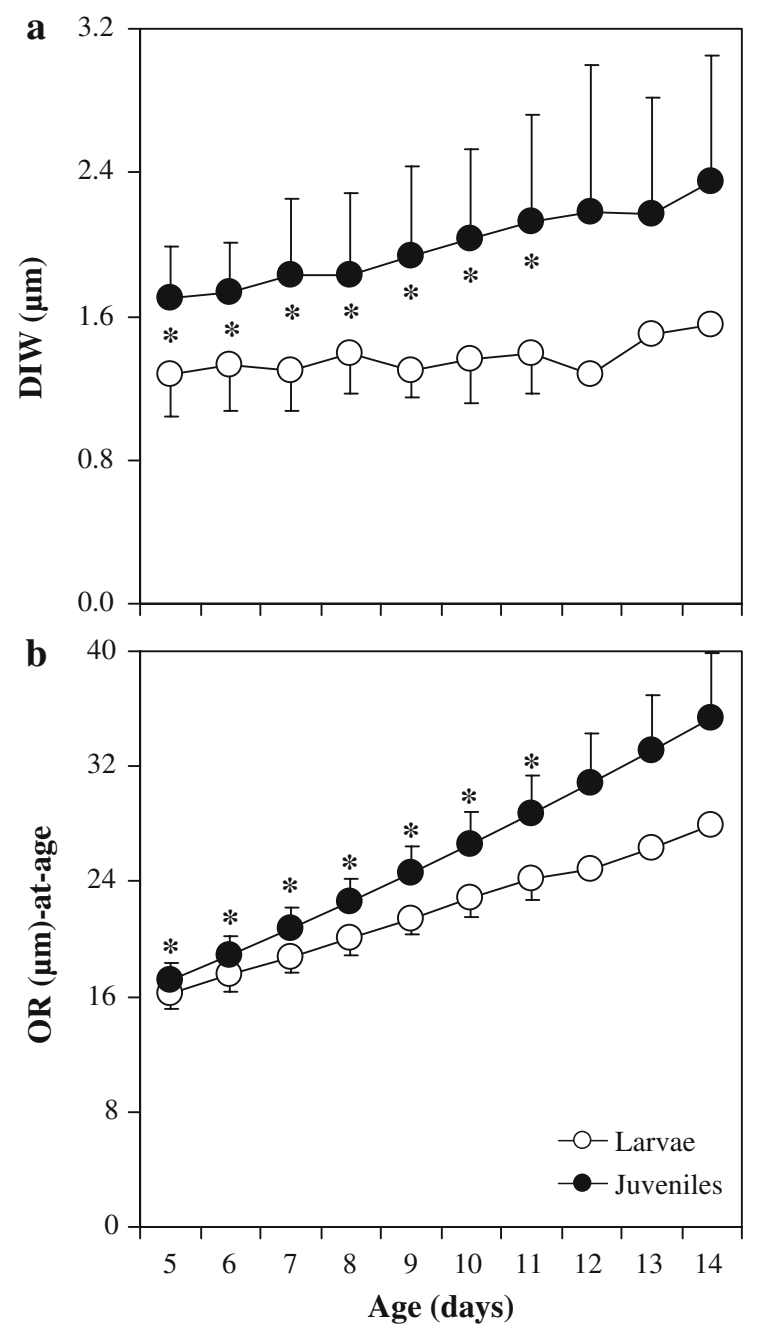

Fig. 3 Mean $( \pm \mathrm{SD})$ otolith daily increment width (DIW; proxy for growth rate), and otolith radius (OR, $\mu \mathrm{m})$-at-age (proxy for size-at-age) during 5-14 days after hatching of larval Japanese seabass collected from the Ariake Bay. Asterisks indicate significant differences between larvae and juveniles at a given age (Student's $t$-test; $P<0.001$ or lower). Statistical test could not be done for 12-14 days of age because of insufficient sample size ( $n=1$ at each age)

ground. Therefore, repeated samplings should capture members of the same population. Moreover, the population of Japanese seabass in Ariake Bay (the Ariake population) is unique in that the Ariake population is reproductively isolated and is restrictedly distributed only in Ariake Bay (Kinoshita et al. 1995; Nakayama et al. 1996). In our study, all larvae hatched in December 2007 but only 16 individuals collected as juveniles hatched in December 2007 and evidently survived from the larval (hatch-month) cohort; most of
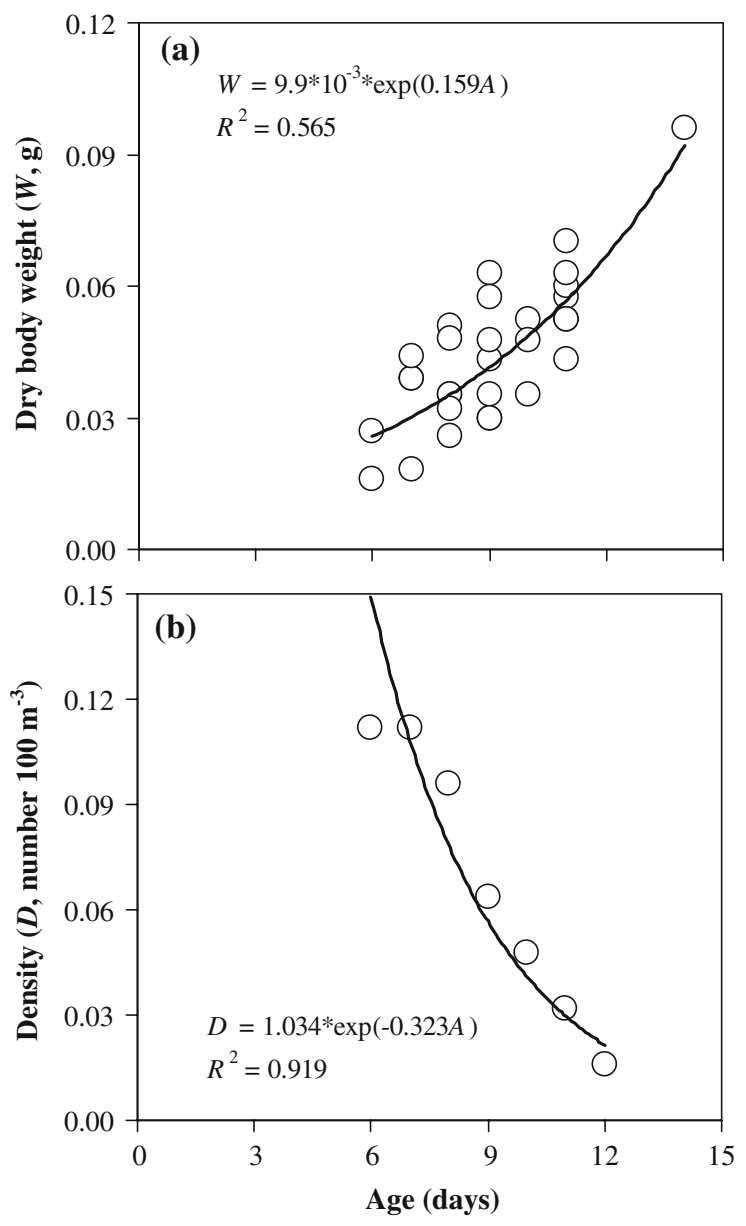

Fig. 4 Relationships of estimated age (days) with a dry body weight $(W, \mathrm{~g})$ and $\mathbf{b}$ with density $\left(D\right.$, number $\left.100 \mathrm{~m}^{-3}\right)$ of larval Japanese seabass collected from Ariake Bay

the other juveniles hatched in January 2008. However, we have included all juveniles in the comparison because we found no difference in the size-at-age and growth rate (during 0-14 DAH) between juveniles hatched in December 2007 and those hatched in January 2008. This clearly indicates that the aforementioned assumption was not violated, or even if violation occurred to some extent it did not affect the comparison between larvae and juveniles.

In general, juvenile density is expected to be lower than larval density for a given species because of high larval mortalities. Nevertheless, higher density of juveniles than larvae is not surprising in species that spawn offshore and their juveniles aggregate in spatially restricted nursery habitats, as in the case of Japanese seabass. Larvae of Japanese seabass are 
highly scattered in the spawning areas as well as during their transportation; in contrast, juveniles concentrate in large numbers in the Chikugo River estuary which is tiny compared to the vast areas of larval habitats. This simply resulted in higher catch of juveniles per unit of effort, and has been reported in previous studies also. In 2001, for example, the density (number $1000 \mathrm{~m}^{-3}$ ) of larvae in the spawning areas was only 2.6 (Hibino et al. 2007) in JanuaryFebruary, but the density of juveniles was as high as 61 in the Chikugo River estuary in March-April (Islam et al. 2006).

The Japanese seabass is a slow-growing species, particularly during the early life stages, as has been found in this study and in other studies (Matsumiya et al. 1982, 1985; Ohta 2004; Shoji et al. 2006, $2007 a, b)$. Mean growth rate at capture of larvae $\left(0.164 \mathrm{~mm} \mathrm{day}^{-1}\right)$, juveniles $\left(0.181 \mathrm{~mm} \mathrm{day}^{-1}\right)$, and the overall growth rate $\left(0.173 \mathrm{~mm} \mathrm{day}^{-1}\right)$ were all within the range $\left(0.130-0.204 \mathrm{~mm} \mathrm{day}^{-1}\right)$ reported in previous works (Matsumiya et al. 1982, 1985; Ohta 2004).

Our study demonstrates that survival of Japanese seabass larvae is growth and size selective, at least during the first 2 weeks of larval life, during which period individuals that survived to become juveniles had significantly higher body size and growth rates than the overall larval population. This means that the larvae that had higher growth rates and body size successfully completed the larval stage to become juveniles. This is consistent with the growth-mortality hypotheses (Anderson 1988; Takasuka et al. 2004) that explain the preferential survival of fast growers by the reduction of the period of time during which young fish are vulnerable to pelagic predators. As complemented and suggested by the "bigger is better" hypothesis (Miller et al. 1988; Bailey and Houde 1989; Leggett and DeBlois 1994), the larger size-at-age of the fast growers provides a survival advantage by reducing vulnerability to predators.

Mean age of the individuals that were transforming from larval stage to juvenile stage was 60 days, suggesting that the larval stage duration (LSD) in the surviving population was $\sim 60$ days (range: $50-73$ days). This is consistent with Shoji et al. (2006) who reported that back-calculated the LSD of juvenile Japanese seabass in the Chikugo River estuary ranged 48-76 days with mean values of $\sim 60$ days during 11 year period. Mean total increment in $\mathrm{OR}$ of juveniles from first feeding to day-60 (OR at day-60 minus OR at day-4) was $151 \mu \mathrm{m}$. On the other hand, mean otolith growth rate (DIW) of larvae during 5-14 days was $1.33 \mu \mathrm{m} \mathrm{day}^{-1}$. With this growth rate, the time that would require for the larvae to reach the transition stage $(151 \mu \mathrm{m}$ OR increment from first feeding) was estimated as 113 days, 53 days more than the LSD of the individuals that already survived to juveniles. The difference in the estimated LSD clearly suggests that the slow-growing and smaller larvae were vulnerable to mortality for a longer period than their fast-growing and bigger conspecifics. Thus, survivors of Japanese seabass exhibited traits consistent with all aspects of the growthmortality hypothesis: faster growth, larger size-atage, and shorter stage duration, i.e., larvae with faster growth, bigger size-at-age, and a shorter larval duration selectively survived the larval period, and this pattern is consistent with several recent studies (Searcy and Sponaugle 2001; Takasuka et al. 2004). The duration in which selection for fast growth occur vary tremendously among species, depending on the species-specific life history, growth and habitat use patterns (Meekan and Fortier 1996; Vigliola and Meekan 2002; Takahashi and Watanabe 2004). In our study, OR-at-age (size-at-age) was consistently higher in juveniles than in larvae throughout 5-14 DAH and the difference increased consistently with age until the 14th day, suggesting that the selection processes operate beyond the 14 days. However, since we did not have larvae of $>14$ days of age, we were unable to determine the exact duration over which selective mortality occurs.

Although size- and growth-dependent mortalities have been commonly reported in recent years, the sizeand growth-based phenomenas are not universal or unidirectional. Contrary to the negative size-selective mortality reported here and in many previous works, there are evidences of positive size selective mortalities mediated by predation (Pepin et al. 2003, Takasuka et al. 2004). Reasons for positive sizeselective mortality may be various (see Takasuka et al. 2004): larger body size and the appearance of melanophores may increase conspicuousness; progress in swimming ability can increase encounter rate with predators; and from the predators' point of view, foraging larger prey would be economic, i.e., larger prey would provide greater return per unit feeding effort. Since pelagic ecosystems generally consist of a 
myriad of predators of various sizes, selective predation must be predator specific and therefore will depend on the prevailing predator field (Takasuka et al. 2007). Hare and Cowen (1997) argued that since the number of predators decreases as predator size increases, larger and faster growing larvae will be less susceptible to predation by the entire predator field. Similar to the role of the predator field, selective mortality must be influenced by prey field also. Selection on a particular fish must be influenced by the number and traits of the co-occurring fishes since they will influence a predator's choice of prey. However, it is inherently impossible to determine how predator and prey field influences selective mortality of a given species in the field.

The estimated instantaneous mortality coefficient $(M=0.323)$ was higher than the weight-specific growth coefficient $(G=0.159)$, resulting in the $M: G$ ratio of $>1.0(M: G=2.031)$. This $M: G$ ratio suggests that the larval cohort was rapidly losing biomass. Changes in the $M: G$ ratio have been suggested as a predictor of a cohort's trend in biomass proliferation and its potential to contribute to recruitment (Houde 1997). Cohort biomass is declining when $M: G>1.0$ and is increasing when $M: G<1.0$. Houde (1997) suggested that most larval cohorts lose biomass rapidly during early life $(M>G)$ until a transition size $(M=G)$ is achieved, after which biomass accumulates $(M<G)$. The $M: G$ ratio links the population dynamics and bioenergetics processes in early life (Houde 1996), suggesting that the $M: G$ ratio is a powerful indicator of larval fitness (Werner and Gilliam 1984) and fish larvae should seek to minimize the ratio, thus maximizing potential for population growth (Houde 1997). Reduction in the $M: G$ ratio can be achieved by minimizing the $M$ or maximizing the $G$ or both. In general, $M$ decreases as $G$ increases (Bailey and Houde 1989), resulting in a negative relationship between growth (therefore, size) and the $M: G$ ratio (Houde 1997). Clearly, recruitment potential in marine fish depends largely on the growth and, therefore, body size during early life, and a correlation between them has been reported in a number of field observations (Hovenkamp 1992; Meekan and Fortier 1996).

We conclude that mortality in Japanese seabass larvae is growth and size selective, preferentially removing slow-growing individuals of a cohort. The $M: G$ ratio suggested that the larval cohort was losing biomass. However, the duration over which selective mortality occurs and the time at which transition between $M$ and $G(M=G)$ is reached, and the cohort starts accumulating biomass could not be determined in this study.

Acknowledgments This research was supported by a grant (ID number: 18380115) provided by the Japanese Society for the Promotion of Science (JSPS). The first author acknowledges the supports provided by the JSPS through a postdoctoral fellowship. Comments from two anonymous reviewers greatly improved the manuscript.

\section{References}

Anderson JT (1988) A review of size dependent survival during pre-recruit stages of fishes in relation to recruitment. $\mathrm{J}$ Northwest Atl Fish Sci 8:55-66

Bailey KM, Houde ED (1989) Predation on eggs and larvae of marine fishes and the recruitment problem. Adv Mar Biol 25:1-83

Campana SE, Jones CM (1992) Analysis of otolith microstructure data. Can Spec Publ Fish Aquat Sci 117: 73-100

Hare JA, Cowen RK (1995) The effect of age, growth rate and ontogeny on the relationship between otolith and somatic size in bluefish, Pomatomus saltatrix, and the implications for the back-calculation of size in the early life history stages of fishes. Can J Fish Aquat Sci 52:1909-1922

Hare JA, Cowen RK (1997) Size, growth, development, and survival of the planktonic larvae of Pomatomus saltatrix (Pisces: Pomatomidae). Ecology 78:2415-2431

Hibino M, Ohta T, Isoda T, Nakayama K, Tanaka M (2007) Distribution of Japanese temperate bass, Lateolabrax japonicus, eggs and pelagic larvae in Ariake Bay. Ichthyol Res 54:367-373

Houde ED (1996) Evaluating stage-specific survival during the early life of fish. In: Watanabe Y, Yamashita Y, Oozeki Y (eds) Survival strategies in early life stages of marine resources. Balkema, Rotterdam, pp 51-66

Houde ED (1997) Patterns and trends in larval-stage growth and mortality of teleost fish. J Fish Biol 51(S-A):52-83

Houde ED, Zastrow CE (1993) Ecosystem-and taxon-specific dynamic and energetics properties of larval fish assemblages. Bull Mar Sci 53:290-335

Hovenkamp F (1992) Growth-dependent mortality of larval plaice Pleuronectes platessa in the North Sea. Mar Ecol Prog Ser 82:95-101

Islam MS, Tanaka M (2006) Spatial variability in the nursery function along a temperate estuarine gradient: role of detrital versus algal trophic pathway. Can J Fish Aquat Sci 63:1848-1864

Islam MS, Hibino M, Tanaka M (2006) Distribution and dietary relationships of Japanese temperate bass (Lateolabrax japonicus) juveniles with two contrasting copepod assemblages in estuarine nursery grounds in Ariake Bay, Japan. J Fish Biol 68:569-593 
Islam MS, Ueno M, Yamashita Y (2009) Otolith microstructure of Japanese sea bass larvae and juveniles: interpretation and utility for ageing. J Appl Ichthyol 25:423-427

Kinoshita I, Fujita S, Takahashi I, Azuma K, Noichi T, Tanaka M (1995) A morphological and meristic comparison of larval and juvenile temperate bass, Lateolabrax japonicus from various sites in western and central Japan. Jpn J Ichthyol 42:165-171

Leggett WC, DeBlois E (1994) Recruitment in marine fishes: is it regulated by starvation and predation in the egg and larval stages? Neth J Sea Res 32:119-134

Matsumiya Y, Mitani T, Tanaka M (1982) Changes in distribution pattern and condition coefficient of the juvenile Japanese sea bass with the Chikugo River ascending. Bull Jpn Soc Sci Fish 48:129-138

Matsumiya Y, Masumoto H, Tanaka M (1985) Ecology of ascending larval and early juvenile Japanese sea bass in the Chikugo River estuary. Bull Jpn Soc Sci Fish 51:1955-1961

Meekan MG, Fortier L (1996) Selection for fast growth during the larval life of Atlantic cod Gadus morhua on the Scotian Shelf. Mar Ecol Prog Ser 137:25-37

Meekan MG, Vigliola L, Hansen A, Doherty PJ, Halford A, Carleton JH (2006) Bigger is better: size-selective mortality throughout the life history of a fast-growing clupeid, Spratelloides gracilis. Mar Ecol Prog Ser 317:237-244

Miller TJ, Crowder LB, Rice JA, Marschall EA (1988) Larval size and recruitment mechanisms in fishes: toward a conceptual framework. Can J Fish Aquat Sci 45:1657-1670

Nakayama K, Kinoshita I, Seikai T, Nakabo T, Tanaka M (1996) Morphological comparisons during early stage rearing of Chinese and Japanese forms of the temperate bass, Lateolabrax japonicus. Jpn J Ichthyol 43:13-20

Ohta $T$ (2004) Ecological studies on the river ascending migration of Japanese sea bass Lateolabrax japonicus in Ariake Bay, on the basis of otolith information. $\mathrm{PhD}$ Thesis, Kyoto University, Kyoto, $126 \mathrm{pp}$

Pepin P, Dower JF, Davidson FJM (2003) A spatially explicit study of prey-predator interactions in larval fish: assessing the influence of food and predator abundance on larval growth and survival. Fish Oceanogr 12:19-33

Robert D, Castonguay M, Fortier L (2007) Early growth and recruitment in Atlantic mackerel Scomber scombrus: discriminating the effects of fast growth and selection for fast growth. Mar Ecol Prog Ser 337:209-219

Searcy SP, Sponaugle S (2001) Selective mortality during the larval-juvenile transition in two coral reef fishes. Ecology 82:2452-2470

Shima JS, Findlay AM (2002) Pelagic larval growth rate impacts benthic settlement and survival of a temperate reef fish. Mar Ecol Prog Ser 235:303-309

Shoji J, Tanaka M (2007a) Density dependence in post-recruit Japanese seaperch Lateolabrax japonicus in the Chikugo River. Mar Ecol Prog Ser 334:255-262

Shoji J, Tanaka M (2007b) Growth and mortality of larval and juvenile Japanese seaperch Lateolabrax japonicus in relation to seasonal changes in temperature and prey abundance in the Chikugo estuary. Estuar Coast Shel Sci 73:423-430

Shoji J, Ohta T, Tanaka M (2006) Effects of river flow on larval growth and survival of Japanese seaperch Lateolabrax japonicus (Pisces) in the Chikugo River estuary. J Fish Biol 69:1662-1674

Takahashi M, Watanabe Y (2004) Growth rate-dependent recruitment of Japanese anchovy Engraulis japonicus in the Kuroshio-Oyashio transitional waters. Mar Ecol Prog Ser 266:227-238

Takasuka A, Aoki I, Mitani I (2003) Evidence of growth-selective predation on larval Japanese anchovy Engraulis japonicus in Sagami Bay. Mar Ecol Prog Ser 252:223-238

Takasuka A, Aoki I, Mitani I (2004) Three synergistic growthrelated mechanisms in the short-term survival of larval Japanese anchovy Engraulis japonicus in Sagami Bay. Mar Ecol Prog Ser 270:217-228

Takasuka A, Oozeki Y, Aoki I (2007) Optimal growth temperature hypothesis: why do anchovy flourish and sardine collapse or vice versa under the same ocean regime? Can J Fish Aquat Sci 64:768-776

Vigliola L, Meekan MG (2002) Size at hatching and planktonic growth determines post-settlement survivorship of a coral reef fish. Oecologia 131:89-93

Werner EE, Gilliam JF (1984) The ontogenetic niche and species interactions in size-structured populations. Annu Rev Ecol Syst 15:393-425 